\title{
The Role of Information Technology Application Research
}

\author{
Zhang Baowei \\ Lixin University of Commerce, West Zhongshan Road.2230, 200235 Shanghai, China \\ zhangbaowei.66@163.com
}

Keywords: Information technology, Physical education, Education

\begin{abstract}
Information technology is a new perspective of physical education teaching reform in china.It is a kind of new teaching way.Putting the information technology into sports teaching, changing the traditional teaching concepts and putting the computer information technology fully into PE teaching are the problems which can't be ignored in physical education. With the rapid development of information technology,Human beings are from industrial society into the information society,so the information technology and physical education are the new viewpoint of PE Teaching Reform in our country,they are closely connected with the traditional course teaching and also have the relative independence of the new teaching way.Research on the integration of information technology and physical education teaching have great realistic significance to the development of sports education in our country.
\end{abstract}

\section{Foreword}

With the rapid development of the science and technology,human being are turning the industrialized society into the information society, so the information technology and physical education teaching is the new viewpoint of sports teaching reform in China, it is closely related with the traditional teaching form, at the same time, the new teaching way has the relative independence. Research on information technology and physical education in the development of physical education in China has great realistic significance.

\section{The meaning of the integration of information technology and physical education}

\subsection{The meaning of the integration of information technology and physical education}

Information technology, in another word, synthetic application of multimedia, network, audio-visual and so on,make quiet and single class become lively and vivid,which activates motive power of teachers learning and students learning. The integration of information technology and physical education teaching means taking the modern information technology as a cognitive tool to experiment of inquiry-based learning and show, organically integrated into the sports teaching process.

It is by no means a simple addition of information technology and curriculum, but rather to take courses as a starting point, let the information technology serve the course.

Its essence is under the guidance of the advanced education idea and theory, especially in the "dominant - subject" education theory, taking the information technology such as multimedia, network, audio-visual equipment as a cognitive tool to promote students' inquiry learning, emotional incentive and create the teaching environment, and apply them into the process of PE teaching organically, make various of teaching resources, teaching elements and teaching through sorting, combination and mutual confluence, on the basis of the whole optimization to produce gathered effect, so as to promote the fundamental change of the traditional teaching method, to cultivate students' innovation spirit and practice ability of targets.

\subsection{The value of the IT and physical education integrated}

Sports course is a college-based courses which the teaching methods is single, in terms of the traditional physical education. The extensive application and the rapid development of information technology brings a new opportunity for us to reform the traditional teaching methods 
and provides a new platform for students to use the knowledge Integratedly.The foothold of IT and physical education should be physical education curriculum, IT services to the physical education which changes the physical education environment and the course of the students and teachers gradually. Emphasizing the areas in which IT can enhance the effect of physical education learning enables students to complete those actions which can't be finished by other methods or allows students to master some of the important skills learned by other methods to achieve the established teaching goals better. Therefore, in the course of Physical Education, PE teachers should make full use of information technology in the graphics, images, animation, audio, video and other functions to provide students with a new sports teaching situation and ues an easy way which students could accept to show elite athletes' ideal standard action by multimedia which enable students to establish the correct technical concepts ,feel the actions in the different time,stimulate students 'thinking in images, enhance students' interest in learning the sport and mobilize the initiative of students. Coupled with the guidance of teachers, students master the action to speed up the process, improve learning efficiency, play a multiplier effect in

Improving the physical quality of classroom teaching, teaching effectiveness.

\section{The model of situation and exploration which we combined imformation technique with physical education}

Information technique now was only used to discuss and solve the problem at the level of macro view.But we didn't completley apply it into education practice of subject.Acorrding to education practice and aiming to the feature of PE, we should combine imformation technique with PE course in order to prove the new model can be used into all physical teaching. The model can help to absolutely stimulate initiative,enthusiasm,creativity of students and it can also let student become real subject and constructor of imformational process and knowledge sense.

\subsection{Establishing the teaching situation, motivate the students' interest}

The athletics teacher wants to be good at making use of a modern information technique means and makes use of its image, vivid, keep the advantage of view, provide vivid for student and keep a view to combine together of hand over to study environment with each other, stimulate the student's various sense organses, use a various teaching method guide student, train the interest of the student to a certain sport, the active and aggressive of the transfer and exaltation student.If"side Chuai leg" in the martial arts acts, the teacher can invite a student first to watch a multi-media action animation and carry on contrast action from the each angle, different on the side and form operative concept in the brain;Or can make use of information technique means, never record the student's action process with angle, after calculator processing, present a stereoscopic picture to carry on a demonstration, let the student carry on a comparison, analytical, stir up the interest that the student studies to the athletics, cause it to seek knowledge desire.Of move most importantly because of.So the novel, diverse sex and interest of the content of course, teaching method and teaching means are the important condition that stirs up student's motive.

\section{2surmount the points and difficulties in sports technology and improve teaching effect}

Physicaleducation is different from other teaching. When teacher is explaining,he should show students the standard demonstration.In the actual sports teaching there are some movements which have complex structure or are needed to be finished suddenly that teachers are difficult to explain in demonstration and students are also hard to understand the points in it. And now the teacher can use Multimedia information technology--a new method of teaching, which observes from different angles, different sides, multi angle, all-round,dynamic actions throug $\mathrm{h}$ the slow motion or frame mode and it can speed up students 'process of mastering what they learn and arouse their willing to put it into practice.Compared with the traditional way .the efficiency has been arised. 


\subsection{Cultivate the spirit of innovation, promote essential-qualities-oriented schooling}

Imformation technique and physical education is an effective way to cultivate sports training innovative talents and implement essential-qualities-oriented schooling. In physical education, teachers should bring imformation technique into full play, promote the cultivation of innovation, break the traditional teaching philosophy, stimulate students' sense of innovation constantly, arouse their curiosity and thirst for knowledge, and at the same time give them sufficient chances to practice and explore.Guiding students into deep observation, correcting the wrong action, analyzing the causes of the wrong action and leading them to the correct way timely can make students have a new discovery by observing every time and cultivate their ability to identify problems so that the needs of solving problems can be produced, and the practicing ability to solve problems can be improved. Teachers can also allow students to put the theoretical knowledge learned into practice by thinking, encourage them to innovate actively and think hard for a new, fit ,lively and funny activities, in which process the students should be inspired and helped timely. Over time, the students ' strong interest in IT means inevitably translate into active participation, and these actions will consolidate and strengthen continuously to achieve a balance of physical and mental harmony to improve the quality of students.

\subsection{Making self-assessment and obtaining feedback.}

By using the modern information technology, students can not only learn sports in classrooms, but they can also learn it by themselves after class or doing revision. Students can record their movements or watch them from computers to compare right or wrong. Moreover, using the modern information technology can also motivate student's interests of learning sports, stimulate their initiative and improve the quality and effect of teaching.

\section{The problem of information technology and physical education}

4.1The class which reflect students' main role should be prevented become into a laissez faire classroom, excessively weaken the role of teachers is for achieving the teaching process optimization, causing the student to obtain the best effect of learning, the teacher's leading role is indispensable, and avoiding the one-sided emphasis on student centered, completely let the students to explore, but ignore the role of the teacher. In the multimedia and network technology as the core of the information technology environment, cultivating students' information literacy and ways of thinking, strengthening information acquisition, information analysis, information utilization, and the understanding of information ability, information technology become their learning tools, tools for thinking, to express their views tools etc. In the teaching activities give full play to the dominant position of students in learning, make students explore independently, cooperation and communication, and take the initiative to question, to improve their information literacy, improve judge things, problem solving skills, develop good thinking habits, and many other aspects.

4.2 Requires teachers to improve their own quality, and master the computer basic operation and its related domain knowledge, master the multimedia teaching material production technology under the information technology environment, the teacher is the creation of teaching situation, information technology study guides.

Teachers should pay attention to stimulate students' interest, creating teaching situation in the teaching activities designed to emphasize the emphases and difficulties of reflect teaching, reflect the effect after the activity participation.

Teaching high school students as the main body of learning, is not to give up the teacher's leading role, especially when the students' information literacy is not very high, teacher's dominant position becomes more important.

So teachers should constantly improve their own quality, strengthening the study of modern information technology, only in this way can manage well in the classroom teaching methods, optimize the classroom teaching, improve teaching quality. 


\section{References}

[1]Jianping Zhang. Integration of computer technology and the College Physical Education[J] Beijing Sports University Newspaper, 2002 (5): 685-686

[2]Guoyue Li, The thinking of using information technology to promote the modernization of College Physical Education [J] Guangzhou Sport University academic journal, 2003 (1): 126-128

[3]Wen Du, Xianwei Pang .Design and application of sports courseware with network conditions [J] Chengdu Institute of Physical Education Newspaper, 2002 (5): 62-63

[4]Cuncao Sun.Experimental studies students creative thinking and practical ability in physical education [J] Shenyang Institute of Physical Education Newspaper, 2003 (1): 69-71

[5] Rude Liu, Qi Chen. Computer integration in education: as a learning object, learning tools and teaching tools [J] AVE research, 199 (11). 